\title{
In-home support or out of home care? Thresholds for intervention with abused and neglected children
}

Nina Biehal, Helen Baldwin, Linda Cusworth, Jim Wade and Victoria Allgar

Accepted for publication by Children and Youth Services Review

\begin{abstract}
The number of children referred to the English child protection system and the numbers receiving home-based intervention or placed in out of home care have been rising in recent years. It is difficult to judge whether these changes indicate that thresholds for intervention are low or high, as we know little about the severity of the maltreatment that draws children into the child protection system in England. This study compared the histories, circumstances and pathways of children receiving quasi-compulsory home-based support (under a child protection plan) to those for children ever placed in out of home care. It collected detailed data from the social workers of 390 children and is the first UK study to include a standardised measure of the severity of maltreatment, the Modified Maltreatment Classification System (MMCS). It found that the vast majority of children had experienced multiple types of maltreatment, including at least one type of high severity, suggesting that thresholds for the use of child protection plans and placement were high. The strongest predictors of placement (as opposed to home-based support) were severity of maltreatment, being unborn or under one year old at referral, being disabled and experiencing physical abuse. Findings are discussed in the context of developments in policy and services under the English government's austerity programme.
\end{abstract}

Key words

Child protection plans; maltreatment severity; placement 


\section{Introduction}

The number of children involved in the English child protection system has risen sharply since 2008, with an increase in referrals, investigations, child protection plans, applications for care and in children placed away from home (Department for Education, 2010, Department for Education, 2017a, Department for Education, 2017c). These developments have led to concern about the capacity of services to respond, especially in the context of funding pressures arising from the government's austerity programme introduced in 2010. There are also concerns about the implications for children and families. The rise in child protection activity may be an indicator of falling thresholds for intervention, which might result in some children being drawn into the child protection system without good reason. Alternatively, thresholds for intervention may be rising as agencies struggle to respond to increased demand, which may mean that some children fail to get the support they need. The picture is complicated by local variation, which has led to concerns that thresholds are set too low in some local authorities, leading to inappropriate referrals, and too high in others, leaving children at risk (National Audit Office, 2016). This paper examines thresholds for the use of two child protection interventions, comparing the histories and circumstances of maltreated children admitted to out of home care to those for others supported at home on a child protection plan. ${ }^{1}$

\section{Background to the study}

Changes in the number of children drawn into the child protection system are not new. The number on child protection registers fell by $25 \%$ between 1994 and 2004 before gradually starting to rise again (Department for Education and Skills, 2004). ${ }^{2}$ Similarly, the population of children in out of home care fell more or less steadily from 1980, reaching a low point in 1994 before rising again. The marked rise in children in out of home care from 2008 is therefore the continuation of a longer-term, albeit fluctuating, trend. Changes in the size and composition of the care population from the mid-1960s to late 1980s were strongly, influenced by shifts in policy and institutional frameworks, especially in relation to youth offending, and also by high profile child deaths from abuse (Rowlands and Statham, 2009). Subsequent changes have been largely, though not solely, policy-driven. The Children Act 1989 tightened the legal grounds and legal process for the removal of children and introduced the concept of pro-active family support, reframing the earlier concept of prevention introduced by the Children and Young Person's Act 1963. This led to a decline in the 'flow' of children into out of home care during the early 1990s, accompanied by a rise in the 'stock' of children in placement on the annual census date. The raising of thresholds for compulsory intervention by the 1989 Act meant that fewer children were entering care, but those who did were being admitted for more serious reasons and therefore staying longer (Rowlands and Statham, 2009, Department for Education and Skills, 2003).

\footnotetext{
${ }^{1}$ Out of home care will be abbreviated as $\mathrm{OHC}$ and child protection plan will be referred to as CPP.

${ }^{2}$ Data on the years subsequent to 2004 were taken from the annual government statistics on children on the child protection register or (subsequently) on child protection plans, for the years 2005-2017.
} 
Wider changes in child protection policy and practice have to some extent been driven by child deaths from abuse, which have been followed by the publication of Serious Case Reviews and in some cases by public inquiries (Parton, 1985, Lord Laming, 2003). The death of Baby Peter in 2007 received considerable media and government attention and led to a high profile official inquiry (Lord Laming, 2009). Public scrutiny of the child protection system following Baby Peter's death almost certainly contributed to the increase in referral and intervention from 2008, perhaps reflecting a shift to more cautious practice on behalf of referring agencies and social workers. However, Baby Peter's death was unlikely to be the sole reason for the increases as these began several months before his death was made public (Macleod et al., 2010).

There have been competing claims that the recent rise in investigation and intervention reflects improved recognition of need or, alternatively, unnecessary over-intervention in family life. These debates echo long-standing concerns about thresholds for investigation and service provision. Studies conducted in the early 1990s reported that too many families were being placed on the child protection register without receiving the help they needed and, more recently, the Munro report argued that the child protection system had become risk-averse and called for a greater emphasis on providing early help (Gibbons et al., 1995a, Department of Health, 1995, Munro, 2011). Studies of administrative data have similarly suggested that there is too much attention to investigation and risk management and too little to providing early support to families, with many children being drawn into the net of the child protection system as a result (Bilson and Martin, 2017, Hood et al., 2016). However, studies of local authority practice have argued that the rise in rates of intervention reflects improved recognition of need. They found evidence of greater attention to child sexual exploitation and long-standing neglect over the past few years, as well as a rise in referrals from the police concerning the impact of domestic violence on children (Brooks and Brocklehurst, 2010, Brooks and Brocklehurst, 2014, Macleod et al., 2010).

Without evidence of the severity of the maltreatment to which the child protection system responds, it is difficult to assess whether thresholds for intervention are either high or low. Although an epidemiological study has investigated risk factors for maltreatment (Sidebotham and Heron, 2006) and some studies have provided valuable evidence on the nature and extent of the maltreatment children experience (Brandon et al., 1999, Ward et al., 2006, Farmer and Owen, 1995), we have identified only two UK studies that have attempted to systematically measure maltreatment severity. One drew on agency ratings of physical abuse, categorising cases as fatal, serious or moderate, while another devised a simple measure of the severity of physical and sexual abuse (Gibbons et al., 1995b, Gibbons et al., 1995a). Furthermore, few UK studies have addressed the possibility that children may experience more than one type of maltreatment (Lutman and Farmer, 2013, Biehal et al., 2015). Some studies in the USA have used a standardised measure, the Modified maltreatment Classification System (MMCS), to investigate the severity of maltreatment, but their findings cannot be directly extrapolated to England due to the variation in policies, systems and wider contexts between the two countries (Litrownik et al., 2005, English et al., 2015, English et al., 2005, Pears et al., 2013). 
We therefore know little about the severity of maltreatment experienced by children in the English child protection system. Nor do we know whether, and how, maltreatment types and severity are associated with the use of different interventions. In particular, there has been very little research on the histories and circumstances of children who are supported at home on child protection plans. Without evidence of this kind, it is difficult to judge where thresholds for intervention lie.

\section{Aims and context for the study}

This paper presents initial findings from a wider study, which compared outcomes for children admitted to out of home care $(\mathrm{OHC})$ to those for maltreated children (and those at high risk of maltreatment) who remained at home on a child protection plan. This article draws on the study's extensive data on the histories, circumstances and pathways of these children in order to provide insights into recent thresholds for the use of child protection plans and OHC. It presents an analysis of:

(a) Pathways into and through the child protection system for children referred before the age of eight years;

(b) The histories and circumstances of children at risk of abuse or neglect who enter out of home care, compared to those for children assessed as at risk of maltreatment who remain at home on a Child Protection Plan.

A Child Protection Plan (CPP) is a multi-agency plan, agreed at a child protection case conference, to address concerns about children's safety and well-being and support them to remain at home (HM Government, 2015). Although a CPP is not a compulsory intervention it is effectively a quasi-compulsory measure, as parents are undoubtedly aware that noncompliance might potentially result in an application to the court to remove the child. CPPS are typically a short-to medium term measure, with over half lasting for six months or less and the vast majority for less than a year.

It is important to note the wider context in which CPPs and $\mathrm{OHC}$ are used. Any child whose case is open to children's services is defined as a child in need (CIN) and may therefore be eligible for family support services provided on a voluntary basis under s.17 of the Children Act 1989, although it is unclear how many actually receive these. In March 2017, 330 children per 10,000 under-18 years old were recorded as children in need and, in just over half of these cases, the reason for referral was abuse or neglect. On that date, 43 children per 10,000 were on a CPP (13\% of all CIN) and a further 62 per 10,000 were 'looked after' in OHC, of whom 61\% were placed due to abuse or neglect (Department for Education, 2017c, Department for Education, 2017a).

\section{Design and methods}

The study was a natural experiment designed to compare histories and outcomes for two naturally occurring groups of children referred due to concerns about maltreatment before the age of eight years: those placed in $\mathrm{OHC}$ and those supported at home on a CPP and never admitted to OHC. It employed a catch-up design, linking administrative data from the date of the child's initial referral (baseline), primary data from a survey of social workers and 
interview data collected from the current caregivers of 390 children at follow-up. Median length of follow-up from date of initial referral to date of interview with the child's caregiver was 5.1 years (range 11 months to 9.5 years). Median age at follow-up was 6.8 years (ranging from 2.5 - 9.8 years).

\subsection{Sampling}

This was a case study of a single local authority. Our original plan was to identify and follow up maltreated children in a local cohort study, which had collected socio-economic and health data from the mothers of over 11,000 children during pregnancy. However, the plan changed when few cohort children placed on a CPP or in OHC were identified at recruitment. Instead, anonymised administrative data were used to identify all children born in the area between 1st September 2005 and 31st August 2012 who, by August 2014, had (a) been the subject of a CPP and/or (b) entered OHC due to maltreatment $(n=1,801)$. The local authority provided updated administrative data on these children in August 2015. Children who had left care through adoption $(n=278)$ or a special guardianship or residence order $(n=124)$ and children who had died $(n=4)$ were excluded. The final sampling frame $(n=776)$ included all children currently in care (204) or reunified with their families by the date of recruitment (263), and a one-in-three random sample of the 928 children who had never been in $\mathrm{OHC}$.

Children were included in the sample once an interview was completed with their current caregiver (parent or foster carer). The final sample $(n=390)$ comprised 216 children who had entered $\mathrm{OHC}$ before they were eight years old (including 92 reunified with families by the interview date) and 174 who had been the subject of a CPP but never entered OHC. Caregivers of the remaining children could not be interviewed due to contact details being out-of-date/inaccurate ((25.5\% of sampling frame) or refusal (8.4\%). The sample was representative of children in the area who had been the subject of a CPP or entered OHC, as all entrants to $\mathrm{OHC}$ plus a random sample of those on CPPs but never in $\mathrm{OHC}$ were included in the sampling frame. Furthermore, the overall response rate of $50.3 \%$ was high for this population ( $81 \%$ for children in $\mathrm{OHC}$ at follow-up and $48 \%$ for those living with their families). Analysis of administrative data found no significant differences between those recruited/not recruited in relation to age at first referral and first intervention, sex, ethnicity and number of episodes of involvement with services.

\subsection{Data collection and ethics}

Data extracted from local administrative datasets were linked to primary data from social workers and caregivers. The survey company TNS-BMRB conducted face-to-face interviews with the current caregivers (parents, relatives or foster carers) of 390 children in 2015, which focused principally on the children's current development and wellbeing. Data on children's histories and current status were gathered via an online survey of social workers, who were advised to consult the children's case files to avoid recall bias. Case file analysis was conducted if no social worker was available. This paper draws on our analysis of the survey and administrative data. 
The social worker survey included a measure of maltreatment type and severity, the Modified Maltreatment Classification System (MMCS), a standardised instrument developed in the USA and used by the LONGSCAN group of studies and some others. Social workers were asked to indicate the highest severity of each type of abuse or neglect ever experienced by assigning each child a score on a scale ranging from zero (no experience of this type), 1 (lowest severity) to 5 (highest severity). To standardise scoring, the MMCS materials provide detailed guidance on grading the severity of each maltreatment type. For example, in relation to sexual abuse, the manual states that exposing a child to 'explicit sexual stimuli or activities, although the child is not directly involved' should be coded as 1 , engaging a child in' mutual sexual touching' should be coded as 3 and 'forced intercourse or other forms of sexual penetration' as 5 (English and the LONGSCAN investigators, 1997). ${ }^{3}$ Similar ratings are provided for all types and sub-types of maltreatment.

We then created a measure of maltreatment severity that took account of all four types. Various strategies have been used to create comprehensive scores using the MMCS, such as summing separate scores to create a total score (Litrownik et al., 2005, Lau et al., 2005). However, with this approach a child exposed to severe maltreatment of just one type might have a lower total severity score than a child exposed to multiple types of low-severity maltreatment. Our own solution was simpler. We constructed a binary rating of severity for each child based on the highest MMCS score for any type of maltreatment experienced. A score of 3-5 for at least one type was taken to indicate high severity maltreatment and a maximum score of 2 for all types indicated less severe maltreatment.

Ethical approval was given by the ethics committee of the University of York's Department of Social Policy and Social Work. The local authority provided anonymised administrative data on the sample and forwarded recruitment materials and requests for consent to the sharing of contact details to caregivers on behalf of the study team. The researchers obtained written consent to interview and to data linkage. All data were anonymised and securely stored, consistent with national guidelines on data protection.

\subsection{Analysis}

Since some children may be the subject of a CPP at one point in their lives and enter $\mathrm{OHC}$ at another, we compared children ever placed in OHC to others who had a CPP but never entered $\mathrm{OHC}$. Chi-square tests were used to compare nominal data between groups and Mann-Whitney $\mathrm{U}$ tests to compare severity scores and other interval data.

Two-step cluster analysis (a form of latent class analysis based on hierarchical clustering) was used to identify naturally occurring groups of children with different histories of maltreatment. The algorithm identifies groups of cases that exhibit similar response

\footnotetext{
${ }^{3}$ Just three examples are provided here for illustration, but the MMCS manual provides ratings for numerous examples of acts or omission for each type, or sub-type, of maltreatment.
} 
patterns. Typically, cases are assigned to the cluster with the nearest centre. Segment membership is then determined by the distance of the respondent to the closest non-noise cluster and to the noise cluster. The pre-cluster stage groups the respondents into several small clusters. The cluster stage uses the small clusters as input and groups them into larger clusters. Based on well-defined statistics, the procedure can automatically select the optimal number of clusters given the input variables. The "best" cluster solution was assessed using the Bayesian information criterion (BIC). The changes in $\mathrm{BIC}$ and changes in the distance measure were evaluated. The aim is to find the number of clusters at which the $\mathrm{BIC}$ becomes small and the change in $\mathrm{BIC}$ between adjacent number of clusters is small. The six-cluster model was identified as the best goodness of fit which had the highest value for the ratio of distance measures (3.095). In the seven-cluster model the ratio was 1.179.

In order to measure the association level, crude odds ratio (OR) and the $95 \%$ corresponding test-based confidence interval $(\mathrm{Cl})$ were calculated using a logistic regression model where, if the probability of there being an association was $<0.1$ in the univariate analysis, then the variables were entered in the regression model. A p-value of $<0.05$ was considered to indicate statistical significance. Analyses were performed on IBM SPSS Statistics for Windows, Version 24.0.

\section{Results}

We compared 216 children who had ever entered out of home care due to concerns about maltreatment to 174 who had been the subject of a child protection plan and had not entered care by follow-up. For brevity, we refer to these as the ever in care and never in care groups. All were under the age of eight years old at the time of first referral.

\subsection{Child characteristics and circumstances at referral}

The study took place in a large metropolitan area with a high level of deprivation and an ethnically diverse population. Nearly two-thirds are white British and $20 \%$ are of South Asian (mainly Pakistani) origin, a three-generation community long-settled in the area. Gender and family structure were not associated with admission to OHC, but children of South Asian origin were less likely to be ever in care than white children (39\%, compared to $57 \%$, $\left.p=0.001, X^{2} 6.990, d f 1\right)$.

Nearly one-quarter of the children $(23 \%, 90)$ were disabled or had a serious long-term health condition. Their conditions included Foetal Alcohol Syndrome (FAS), Neo-Natal Abstinence Syndrome, sensory impairments, disabilities and other developmental delay. Half of these children experienced two or more conditions and for almost one in five (17), these difficulties were accompanied by serious health problems. Children with disabilities and/or health problems were significantly more likely to enter OHC ( $71 \%$ compared to $51 \%$ of those with no disability, $p=0.001, X^{2} 10.638$, df1). Qualitative data from social workers suggested that, for over one-third (31) of these children, their conditions may have been a consequence of neglect or physical abuse. This was clearly the case for the children born with FAS (17) or Neo-Natal Abstinence Syndrome (2). Others had a brain injury or sensory 
impairment caused by shaking (3), serious health conditions exacerbated by medical neglect (7) or were reported to be developmentally delayed due to a lack of stimulation (2). ${ }^{4}$

There were no significant group differences regarding the children's caregivers at referral. Half were living with both parents at referral and one-quarter were living with a lone mother, as shown in Table 1.

${ }^{4}$ These figures may be an underestimate details on the children's disabilities or health were not provided for all of the children. 
Table 1 Child characteristics and circumstances at referral by group

\begin{tabular}{|c|c|c|c|}
\hline & $\begin{array}{l}N(\%) \text { of group never } \\
\text { in care }(n=174)\end{array}$ & $\begin{array}{c}N(\%) \text { of group } \\
\text { ever in care }(n=216)\end{array}$ & $\begin{array}{l}\text { N (\%) of sample } \\
(n=390)\end{array}$ \\
\hline \multicolumn{4}{|l|}{ Ethnic origin $n=387$} \\
\hline White & $110(63)$ & $143(67)$ & $253(65)$ \\
\hline South Asian origin & $44(25)$ & $28(13)$ & $72(19)$ \\
\hline Mixed origin & $20(12)$ & $35(16)$ & $55(14)$ \\
\hline Black & 0 & $7(3)$ & $7 \quad(2)$ \\
\hline \multicolumn{4}{|l|}{$\operatorname{Sex} n=390$} \\
\hline Female & $85(49)$ & $102(48)$ & $187(48)$ \\
\hline Male & $89(51)$ & $114(52)$ & $203(52)$ \\
\hline $\begin{array}{l}\text { Disability and/or long-term health } \\
\text { condition } n=351\end{array}$ & $26(15)$ & $64(30)$ & $90(23)$ \\
\hline \multicolumn{4}{|l|}{ Caregivers at referral $n=390$} \\
\hline Both parents & $97(56)$ & $99(46)$ & $196(50)$ \\
\hline Lone mother & $39(22)$ & $62(29)$ & $101(26)$ \\
\hline Mother + partner & $20(12)$ & $28(13)$ & $48(12)$ \\
\hline Father & $2(1)$ & $3(1)$ & $5(1)$ \\
\hline Parent + relatives & $11(6)$ & $10(4)$ & $21(5)$ \\
\hline Grandparents & $1(1)$ & $4(2)$ & $5(1)$ \\
\hline Removed at birth & $2(1)$ & $8(4)$ & $10(3)$ \\
\hline Other & $2(1)$ & $2(1)$ & $4(1)$ \\
\hline \multicolumn{4}{|l|}{ Age group at 1st referral $(n=390)$} \\
\hline Pre-birth & $37(21)$ & $80(37)$ & $117(30)$ \\
\hline 0-11 months & $40(23)$ & $55(26)$ & $95(24)$ \\
\hline $12-36$ months & $52(30)$ & $52(24)$ & $104(27)$ \\
\hline $37-60$ months & $35(20)$ & $24(11)$ & $59(15)$ \\
\hline $61-87$ months & $10(6)$ & $5(2)$ & $15(4)$ \\
\hline
\end{tabular}




\subsection{Pathways through the child protection system}

Age at first referral ranged from pre-birth to just over seven years, as shown in Table 1, with a median age at referral of just 22 months (excluding unborn children). Over half were first referred when unborn or before they were one year old and over $80 \%$ by the time they were three years old. Many families were already known to services due to the previous maltreatment of siblings. Nearly one-fifth (39) of children ever in care had siblings who had previously been removed and in just over one-quarter (11) of these cases the sample child was removed at birth. Evidence from other English studies suggests that a substantial minority of children are removed in similar circumstances (Masson et al., 2008, Broadhurst et al., 2015).

Nearly one-third (117) were initially referred pre-birth and, for just under $40 \%$ of this group, the initial referral arose from concerns about neglect in utero due to drug or alcohol misuse. For some unborn children, referral was prompted by concerns about domestic violence, parent mental health or the maltreatment of siblings. Only ten of the unborn children became the subject of a pre-birth CPP, with the majority were recorded solely as 'children in need'. However, despite early assessment, $81 \%$ of those initially referred pre-birth subsequently went on to experience maltreatment and $68 \%$ were placed in OHC. Few children referred as infants (under age one) were placed on a CPP or in OHC solely due to the abuse or neglect of siblings as virtually all of this group themselves experienced maltreatment. By the time they were 18 months old, a substantial minority had experienced neglect (27\%), physical abuse (26\%), emotional abuse (35\%) and/or sexual abuse (2\%).

In many cases attempts had initially been made to support children in their families, as half (109) of those ever in care had been the subject of a CPP and in most cases the CPP had been tried first. Recurring concerns led to multiple referrals for nearly half of the children, with $40 \%$ referred $2-4$ times and $8 \%$ five or more times. Re-referral may have been prompted by changes in family circumstances and/or new information about the level of risk, but it is also possible that some cases were closed too rapidly, before problems had been fully identified or adequately addressed.

Children referred pre-birth or before the age of one year were more likely to enter OHC than those referred at an older age $\left(p=0.001, X^{2} 17.570, d f 4\right)$. The high proportion of these children who entered $\mathrm{OHC}$ due to ill-treatment indicates that they remained at home for a time after birth, whereas children removed at or shortly after birth were more likely to have been adopted and therefore lost to the study. The majority (90\%) of those ever in care had only a single admission and, for a substantial minority the experience of placement was fairly brief, as $9 \%$ were reunified with their families within one month and $20 \%$ within six months. However many stayed longer, with $56 \%$ spending two or more years in OHC (with a median total duration of all placements of 28 months). 


\subsection{Dimensions of maltreatment}

For $15 \%$ (60) of the children there was no recorded maltreatment. For most of this group concerns centred on parental substance misuse, domestic violence and/or mental health problems and in half of these cases siblings had been maltreated.

Data on lifetime maltreatment were collected for the 330 children with recorded abuse or neglect. Consistent with national data on CPPs, neglect and emotional abuse were by far the most common types, followed by physical and then sexual abuse, as shown in Table 2 (Department for Education, 2017a).

Table 2 Types of maltreatment by group $n=330$

\begin{tabular}{lcccc}
\hline Type & $\begin{array}{c}\mathrm{n}(\%) \text { of group never } \\
\text { in care }(\mathrm{n}=142)\end{array}$ & $\begin{array}{c}\mathrm{n} \text { (\% of group ever } \\
\text { in care }(\mathrm{n}=188)\end{array}$ & $\begin{array}{c}\text { Total } \mathrm{n}(\%) \\
\text { with each type }\end{array}$ & $\begin{array}{c}\text { Severity by type } \\
\text { Mean (SD) }\end{array}$ \\
\hline Neglect & $108(76)$ & $161(86)$ & $269(82)$ & $3.03(1.266)$ \\
Emotional abuse & $109(77)$ & $135(72)$ & $244(74)$ & $3.05(1.108)$ \\
Physical abuse & $53(37)$ & $93(50)$ & $146(44)$ & $2.53(1.238)$ \\
Sexual abuse & $15(11)$ & $13(7)$ & $28(8)$ & $2.18(1.124)$
\end{tabular}

Children of South Asian origin were less likely to experience neglect, which was reported for $62 \%$ of them compared to $86 \%$ of white children ( $p<0.001, X^{2} 17.105$, df1). Nearly threequarters (71\%) of the children had experienced multiple types of maltreatment: $38 \%$ experienced two types, $29 \%$ experienced three and $4 \%$ experienced all four. However, the number of types was not associated with the likelihood of placement.

The study used the Modified Maltreatment Classification System (MMCS) to measure the severity of the maltreatment experienced by each child, as outlined in section 4.2. Using the MMCS coding scheme, the highest severity of each type of maltreatment ever experienced was rated on a scale ranging from zero (no experience of this type), 1 (lowest severity) to 5 (highest severity), (English, 1997). The 60 children with no recorded maltreatment assigned scores of zero for all types. As Table 2 shows, mean severity scores were higher for neglect and emotional abuse than for physical or sexual abuse.

A binary rating of severity was constructed to provide a 'highest severity' score for each of the 330 children with recorded maltreatment based on the highest MMCS score assigned, as described in Section 4.2. A score of 3-5 for at least one type was taken to indicate high severity maltreatment while a score of 1- 2 for all types indicated less severe maltreatment. The vast majority (82\%) experienced high severity maltreatment of at least one type (rated 3-5 on the MMCS) and 50\% experienced at least one type of very high severity (rated 4-5). Over $60 \%$ of the children initially referred pre-birth went on to experience severe maltreatment, which may help to explain the high rate of placement for this group.

Among those with recorded maltreatment, children ever in care were more likely to have experienced neglect and physical abuse than those never in care $\left(p=0.028, X^{2} 4.836\right.$, df1 for physical abuse and $p=0.026, X^{2} 4.929, d f 1$ for neglect). They were also more likely to 
experience maltreatment that was severe, as for $88 \%$ of the ever in care group the abuse and/or neglect was rated 3-5 on the MMCS, compared to $74 \%$ for those never in care ( $p<$ $\left.0.001, X^{2} 11.645, d f 1\right)$. In particular, children ever in care had significantly higher ratings for physical abuse $(p=0.031)$ and neglect $(p<0.001)$.

\subsection{Profiles of maltreatment}

The next step was to identify the constellations of maltreatment type and severity experienced by the children. A two-step cluster analysis was run on the types and severity of maltreatment experienced by each child to identify naturally occurring groups of maltreated children, including those with no recorded maltreatment (as outlined in section 4.2). This identified six mutually exclusive clusters of children with similar patterns of maltreatment type and severity, as shown in Figure 1.

Figure 1 Clusters of maltreatment types Per cent $(n=390)$

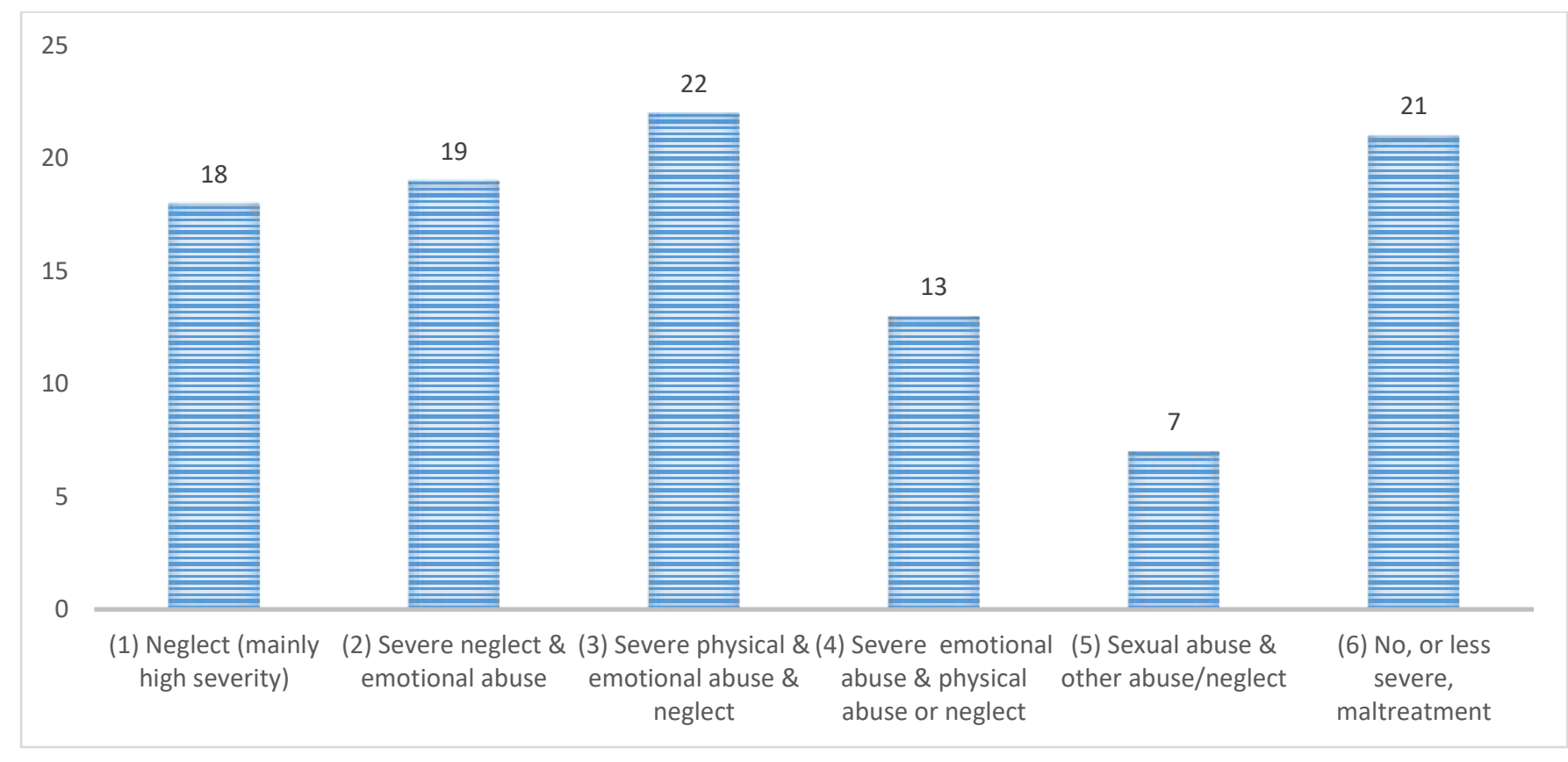

Children were more likely to enter $\mathrm{OHC}$ if they experienced both severe neglect and severe emotional abuse (Cluster 2 ) or severe physical abuse, severe neglect and severe emotional abuse (Cluster 3 ). They were less likely to be admitted if they experienced severe emotional abuse in the absence of other severe maltreatment (Cluster 4 ) or no/low severity maltreatment (Cluster $6,75 \%$ of whom had no recorded maltreatment) ( $p=0.001, X^{2} 20.884$, df5).

\subsection{Parent circumstances}

The children's parents had experienced a complex set of often co-occurring difficulties. There were concerns about parental substance misuse in relation to over half of the children, with three-quarters of parents reported to misuse both drugs and alcohol. Domestic violence was even more common, reported in two-thirds of all cases. Over onethird of parents had mental health difficulties, most commonly depression and anxiety (reported for $62 \%$ and $30 \%$ of parents with mental health difficulties respectively), with personality disorders, bi-polar disorder or schizophrenia reported in smaller numbers of 
cases. In $80 \%$ of cases there were multiple family difficulties, often a combination of domestic violence with substance misuse and/or mental health difficulties. The proportions of cases with reported drug or alcohol misuse or mental health difficulties were significantly higher for the ever in care group, as shown in Table 3.

Table 3 Parental difficulties by admission to care $n=390$

\begin{tabular}{lcccc}
\hline & $\begin{array}{c}\mathrm{n}(\%) \text { of children } \\
\text { never in care }(\mathrm{n}=174)\end{array}$ & $\begin{array}{c}\mathrm{n}(\%) \text { of children ever } \\
\text { in care }(\mathrm{n}=216)\end{array}$ & Total $\mathrm{n}=390$ & $\mathrm{P}\left(\mathrm{X}^{2}\right)$ \\
\hline Mental health & $54(33)$ & $84(44)$ & $138(39)$ & $0.033(4.547)$ \\
Drug misuse & $60(37)$ & $100(52)$ & $160(45)$ & $0.005(7.768)$ \\
Alcohol misuse & $63(39)$ & $104(53)$ & $104(53)$ & $0010(6.625)$ \\
Physical health & $24(14)$ & $45(21)$ & $69(18)$ & $0.52(3.785)$ \\
Learning & $16(10)$ & $30(16)$ & $38(10)$ & $\mathrm{ns}$ \\
difficulties & $108(66)$ & $126(64)$ & $234(65)$ & $\mathrm{ns}$ \\
Domestic violence & & & & \\
\hline
\end{tabular}

As previous studies have found, children whose parents had mental health or substance misuse problems were more likely to enter OHC (Simkiss et al., 2013). Over 90\% of children whose parents misused alcohol or drugs experienced neglect, which was strongly associated with both types of substance misuse $\left(p<0.001, X^{2} 24.566\right.$, df1 for alcohol; $p<0.001, X^{2}$ 28.087, df1 for drugs). There was also an association between parental alcohol misuse and ethnicity, with concerns about parental alcohol misuse reported for far fewer South Asian children (17\%) than white children (55\%). The same was true for parental drug misuse, reported for $24 \%$ South Asian children compared to $50 \%$ of white children $\left(p<0.001, X^{2}\right.$ 30.290, df1 for alcohol; $p<0.001, X^{2} 17.105$, df1 for drugs). Children whose parents were misusing drugs or alcohol had higher scores for maltreatment severity $\left(p<0.001, X^{2} 17.943\right.$, df1) and, perhaps partly because parental substance misuse was less common for the South Asian children, these had lower severity scores than other children $\left(p=0.022, X^{2} 5.213, d f 1\right)$.

Previous research has suggested that parents with learning difficulties are over-represented among parents involved in applications for care (Booth et al., 2005). Learning difficulties were reported in relation to $10 \%$ of parents, as shown in Table 3 , but there was no association between these having these difficulties and the likelihood that the child would be admitted to care rather than supported at home on a CPP.

\subsection{Admission to out-of-home care}

All child and family factors that were significantly associated with admission to $\mathrm{OHC}$ in univariate analyses were entered into an equation using binary logistic regression (Enter method), with ever in care/never in care as the dependent variable. The strongest predictor of admission to $\mathrm{OHC}$ was maltreatment severity. High severity maltreatment (i.e. rated 3-5 on the MMCS) multiplied the odds of admission by almost four and child disability/serious health problems and physical abuse each multiplied the odds of admission by roughly two. 
Younger age at first referral remained a significant predictor of admission in the final model, with children first referred at age one or over less likely to enter $\mathrm{OHC}$ than those first referred pre-birth or when under one year old. This model explained $24 \%$ of the variance in the likelihood of admission to $\mathrm{OHC}$ for children referred due to concerns about maltreatment (Nagelkerke $\left.\mathrm{R}^{2} .242\right) .^{5}$

Table 4 Logistic regression model with ever in care/never in care as dependent variable $n=330$

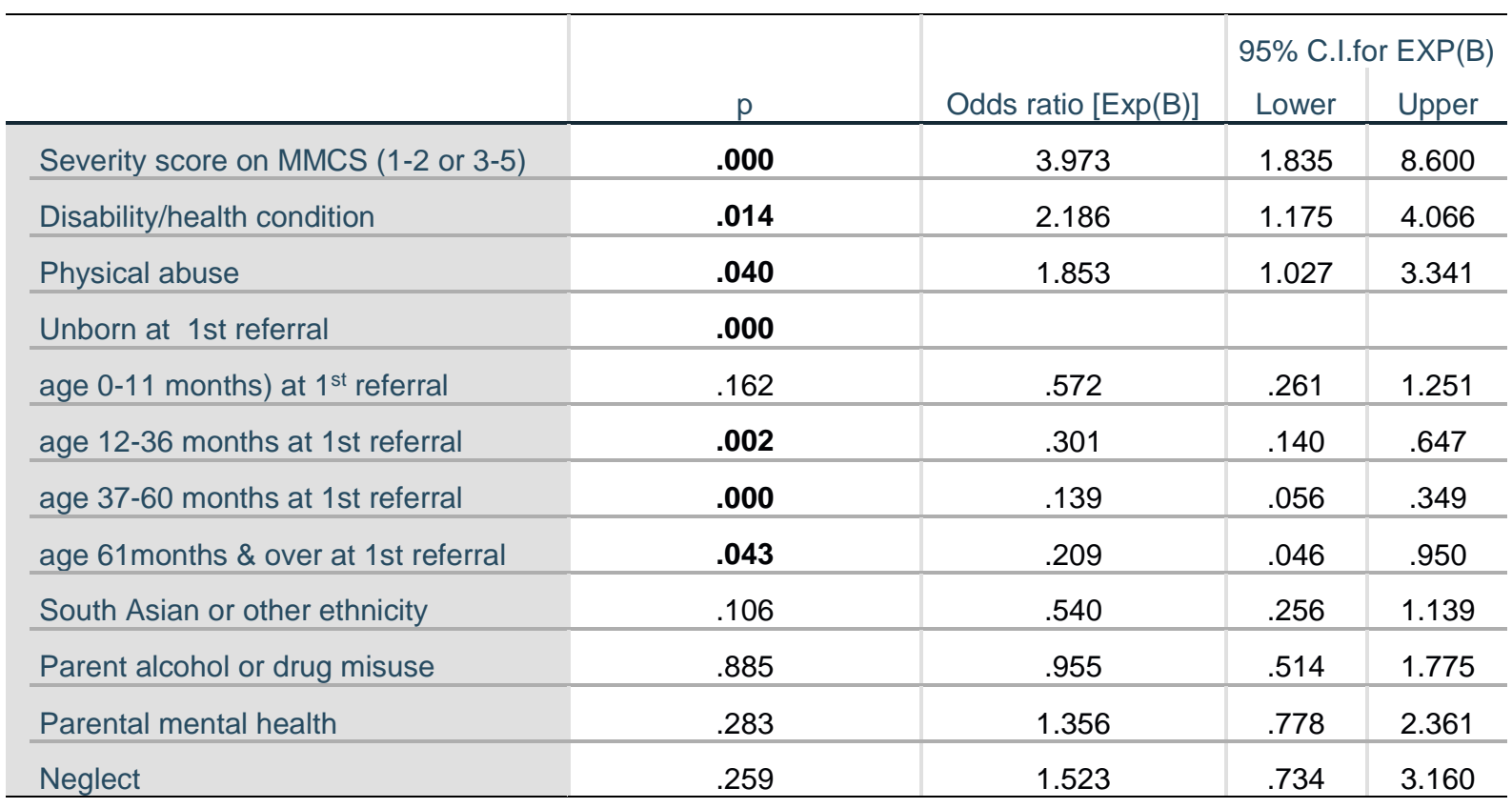

The associations of parental substance misuse and ethnicity with admission to $\mathrm{OHC}$ found in univariate analyses were no longer statistically significant once other factors were controlled for, perhaps because their impact on the likelihood of admission was masked by maltreatment severity. As we saw in section 5.5, children whose parents misused alcohol or drugs were more likely to experience severe maltreatment. The parents of children of South Asian origin were less likely to misuse alcohol or drugs and, on average, their children had lower scores for the severity of maltreatment.

\section{Discussion}

This study provides new evidence on the histories, circumstances and pathways of children placed on CPPs or in $\mathrm{OHC}$ and provides insights into thresholds for the use of these interventions. The severity of the abuse and neglect experienced by $82 \%$ of the children and the multiple types of maltreatment experienced by over $70 \%$ of them suggests that thresholds for the use of CPPs and for placement in OHC were high in the case study authority. Although maltreatment severity has been investigated in the USA and high rates

\footnotetext{
${ }^{5}$ When the six cluster categories were substituted for the separate maltreatment types and MMCS severity scores, no clear pattern was identified.
} 
of poly-victimisation have been reported there, these issues have received barely any attention in the UK (Finkelhor et al., 2007, Pears et al., 2008, Wade et al., 2011, Kim et al., 2016, Lau et al., 2005, Radford et al., 2013, Cecil et al., 2017). The greater likelihood that children ever in care had experienced high severity maltreatment (88\%) compared to those never in care (74\%) suggests, as we might anticipate, that the threshold for placing children away from home was even higher than that for CPPs. Once other significant factors were taken into account, the strongest predictor of admission to $\mathrm{OHC}$ was maltreatment severity. UK studies that have analysed detailed case-level data have similarly reported high thresholds for intervention. They found that placement used very much as a last resort and identified no evidence that children were placed in $\mathrm{OHC}$ without good reason (Masson, 2008, Masson et al., 2013). Of course, maltreatment severity is not the only driver of decisions about intervention, as assessments of future risk are also critical, irrespective of whether children have themselves experienced abuse or neglect. Nevertheless, if thresholds for intervention were low we would expect to find a substantial proportion of children with histories of low severity maltreatment among those on CPPs or in OHC, which was not the case.

Experience of physical abuse almost doubled the odds that children would enter OHC, despite the fact that mean MMCS scores for the severity of physical abuse were lower than those for neglect and emotional abuse. The latter forms of maltreatment are typically chronic and, in the absence of an obvious trigger for action, thresholds for intervention may be higher. This was especially true in relation to placement, as ratings for the severity of neglect were significantly higher for children ever in care. The adversarial nature of care proceedings in England means that there is often a focus on evidence of specific incidents, but critical incidents are less likely to feature in cases of chronic neglect and emotional abuse (Farmer and Owen, 1995, Dickens, 2007).

A significant amount of child protection activity in England involves assessments of risk to unborn or newborn children (Farmer et al., 2011, Masson and Dickens, 2015, Masson et al., 2008, Department for Education, 2017a). Assessment and intervention concerning unborn children in the sample in most cases took place on a voluntary basis. Assessment was often prompted by concerns about current risk to the child in utero due to maternal substance misuse but it was also prompted by concerns about potential risk due to the maltreatment of siblings or domestic violence. In many cases these concerns about the risk of future harm were borne out, as over two-thirds of children initially referred pre-birth went on to experience abuse or neglect. Child disability is also known to be a risk factor for maltreatment (White et al., 2014, Taylor et al., 2016). However, according to social workers, for over one third of children who were disabled and/or had serious health problems, these conditions were a direct consequence of physical abuse or neglect or exacerbated by them. Our evidence therefore suggests that the association between disability and maltreatment may work in both directions.

The lower rate of admission to OHC for children of South Asian origin was not unexpected as they are known to be under-represented in the care population (Owen and Statham, 2009). Our evidence suggests that this may be at least partly due to lower rates of parental 
substance misuse among some South Asian communities. Children of South Asian origin comprised one-fifth of our sample and virtually all of them were from Pakistani (88\%) or Bangladeshi (8\%) backgrounds, so their parents were likely to be Muslim. The likelihood that their parents would drink alcohol was therefore lower than for the other children, as the consumption of alcohol is prohibited by Islam and research has found that Muslim men are less likely to drink alcohol than white-British men and those from Hindu and Sikh communities (Al-Ansari et al., 2016, Cochrane and Bal, 1990, Denscombe and Drucquer, 2000). Substance misuse was strongly associated with neglect and, as we saw in section 5.3, children of South Asian origin were less likely to experience neglect. Furthermore, the neglect that some did experience was typically of lower severity than for white children. Since severe neglect was strongly associated with admission to OHC this, too, may help to explain the lower rate of admission for these children. Our findings therefore suggest that the risk of admission to OHC for children of South Asian origin may, in Muslim communities, be modified by cultural attitudes to the use of alcohol.

Consistent with previous research, parental substance misuse and mental health difficulties were found to be associated with an increased likelihood of placement in OHC (English et al., 2015, Simkiss et al., 2013). However, types of parental difficulty per se were less likely to drive decisions regarding placement than the severity of maltreatment that children (or possibly their siblings) experienced, perceived age- or disability-related vulnerability and evidence of physical abuse, all of which are likely to influence assessments of future risk. Once these factors were controlled for, associations between parental mental health or substance misuse and admission to $\mathrm{OHC}$ were no longer significant. As other studies have reported, the nature of parent difficulties per se appear less likely to influence decisions about placement than parental capacity and co-operation in tackling the problems leading to concerns (Masson et al., 2008, Platt and Turney, 2013, Brandon and Thoburn, 2008, Brandon et al., 2009).

As this was not a longitudinal study, it was unable to investigate any changes in thresholds over time. However, changes in the wider demographic, policy and resource context may help to explain recent thresholds for intervention both in the case study authority and nationally. Increased 'demand' for child protection services may to some extent reflect demographic change, as there has been a significant rise in the child population recent years. In addition, changes in rates of intervention may reflect legal changes and migration flows in the past few years, especially in relation to teenagers. Case law (the Southwark Judgement, House of Lords, 2009) resulted in local authorities acquiring new responsibilities for the placement of homeless 16-17 year olds, which contributed to a subsequent rise in admissions (Brooks and Brocklehurst, 2010). Similarly, a sharp rise in the number of unaccompanied asylum-seeking children in public care in $2015 / 16$, following a policy-driven decline in the number entering the country in the preceding few years, almost entirely accounted for the rise in admissions in that year (Department for Education, 2016a). Some local authorities have also highlighted changes in local levels of need arising from migration from high- to low-rent authorities or from Eastern Europe (Brookes et al., 2016). 
Widening definitions of 'what counts' as abuse are also likely to contribute to the rise in intervention, as there has been increasing policy attention to child sexual exploitation, peer on peer exploitation, trafficking and online grooming for abuse or radicalisation over the last ten years or so. In addition, there has been growing recognition of the potentially harmful effects of neglect and emotional abuse. These were the most common types of maltreatment reported in this study and are also the most common recorded nationally. The proportion of children placed on CPPs $^{6}$ due to emotional abuse rose from $17-37 \%$ between 2002 and 2017, while recorded neglect rose from 39-47\% in the same period (Department for Education, 2017a, Department for Education and Skills, 2004). The steep rise in recorded emotional abuse is likely to stem from growing awareness of the impact that domestic violence may have on children and also from the Adoption and Children Act 2002, which defined witnessing domestic violence as a form of abuse. Growing responsiveness to neglect is similarly likely to be due to growing awareness of evidence on the impact that severe neglect may have on children's health and development, especially for younger children (Brandon et al., 2014, Ward et al., 2012 , Brown and Ward, 2012, Allen, 2011).

In addition, wider government policy since 2010 has almost certainly contributed both to 'demand' for child protection services and to patterns of intervention, both in the case study authority and elsewhere. Cuts in spending on public services under the Coalition and Conservative governments' austerity programme since 2010, and the introduction of greater conditionality in welfare provision, have had a significant impact on levels of need over the last few years. Government welfare reforms have reduced access to housing and social security benefits, reduced the level of these payments in real terms and introduced punitive financial sanctions for minor infringements of benefit rules (Jozwiak, 2017, Fletcher and Wright, 2017). There is increasing evidence that these reforms have contributed to rising poverty and homelessness and a massive increase in the use of emergency food supplies provided by food banks from 2010-2017 (Bradshaw et al., 2017, Fitzpatrick et al., 2017, The Trussell Trust, 2017). Local authorities have reported that rising family poverty, deprivation, homelessness, use of temporary accommodation and stress occasioned by the welfare reforms have had an impact on the number of referrals and that families are presenting with increasingly complex and entrenched problems (Brookes and Brocklehurst, 2014, Brookes et al., 2016).

The changing resource context for children's services has also had an impact on thresholds for services, as there have been successive cuts in government funding for local authorities from 2010, with the most deprived local authorities experiencing the greatest funding cuts (Hastings et al., 2015). As a result, in 2017 the Local Government Association stated that children's social care services were at breaking point and a survey of local authorities reported that $30 \%$ lacked the resources they needed to support children on CPPs or in OHC (Stevenson, 2017, Local Government Association, 2017). One important consequence of

\footnotetext{
${ }^{6}$ Data for 2002 refer to the child protection register, the predecessor of the CPP.
} 
these funding pressures has been that local spending priorities have shifted and many local authorities have been targeting their limited resources on later intervention with children with the most urgent needs, (Brookes et al., 2016). Between 2011 and 2017 there was a fall in local authority spending on early intervention and family support services and a rise in spending on children in OHC and children in need, a group which includes children on CPPS (Department for Education, 2017b, Department for Education, 2016b). Hundreds of children's centres providing open-access support to parents and children have closed and, among those preventive services that remain, there has been a shift to more targeted provision of family support (Action for Children et al., 2016, All Party Parliamentary Group for Children, 2017, Frost et al., 2015, Brookes and Brocklehurst, 2014, McCardle, 2014, National Audit Office, 2016).

In the context of rising demand and diminishing resources, it is perhaps not surprising that thresholds for the use of CPPs and OHC were high in the study authority. However, there is considerable local variation, a phenomenon which has long been evident in relation to rates of placement, reunification and adoption (Dickens et al., 2007, Sinclair et al., 2007). A recent survey of English local authorities found that roughly half reported a rise in the number of children in $\mathrm{OHC}$ during the previous year while others reported a fall, with similar variation in relation to the use of CPPs (Brookes et al., 2016). These variations are to some extent influenced by levels of demand, which tend to be higher in more deprived areas, by available resources and by differences in local approaches (Oliver et al., 2001, Hood et al., 2016). For example, research has shown that local authorities in more affluent areas tend to place a larger proportion of children in $\mathrm{OHC}$ than those in more disadvantaged areas (Bywaters et al., 2015, Bywaters et al., 2017). It has long been recognised that some local authorities may raise thresholds in order to manage demand and there is evidence that in recent years some authorities have pressurised staff to downgrade child protection cases from CPP to the status of 'children in need,' who are eligible for far more limited support (Stevenson, 2015, Stevenson, 2016, Thoburn et al., 1995) . Developments in national policy and their impact both on demand and on resources for services may therefore help to explain our findings that, in terms of the histories and circumstances that drew children into the child protection system, thresholds for intervention were high in the study authority.

\section{Conclusion}

This case study provides insights into the operation of the English child protection system and, specifically, the use of CPPs and placement in OHC. It also provides new evidence on the histories and circumstances of maltreated children supported at home on child protection plans, about whom there has been very little research since the mid-1990s (Farmer and Owen, 1995, Brandon et al., 1999, Brandon et al., 2005, Gibbons et al., 1995a). More is known about children in $\mathrm{OHC}$, but no UK studies have systematically measured the severity of the abuse and neglect that either group has experienced and there has been barely any attention to the configurations in which different types of maltreatment occur.

There has been much discussion of whether thresholds for intervention are too high or too low, as outlined in Sections 1 and 2. Our evidence suggests that thresholds for compulsory or quasi-compulsory intervention with maltreated children appeared to be high in the study 
authority, as the vast majority of children removed from parents or placed on CPPs had experienced serious maltreatment. Possible explanations for this, including the impact of government austerity policies on families and services, have been discussed in the preceding section. While it is not possible to extrapolate from the case study authority to other English authorities, it seems likely that the picture would be similar in at least some of them, as rates of children in $\mathrm{OHC}$ or on CPPs in the study authority were close to the national average.

Evidence of the multiplicity and severity of maltreatment has other implications for policy and practice too, both in relation to local service planning and to the assessment of risks to child development and of children's future needs. Attention to the multiple dimensions of maltreatment also has important implications for research on outcomes for maltreated children, both those in public care and those supported at home. Taking both the severity and co-occurrence of maltreatment types into account will improve understanding of the impact of abuse and neglect on child development and so refine analysis of outcomes for children.

\section{Limitations to the study}

Our findings concern a single case study authority, for reasons set out in section 4.1, so we cannot generalise to England as a whole, especially in view of the evidence on local variation in rates of intervention. However, the study authority was certainly not an outlier in this respect, as the proportions of children on CPPs or in $\mathrm{OHC}$ in the authority are close to the national average (Department for Education, 2017c, Department for Education, 2017a).

The study focused on children referred before they were eight years old. While its findings may also apply to older children, caution is needed in generalising from its results to children in other age groups. The large sub-sample of children of South Asian origin made it possible to compare the experiences of this group to white children but other ethnic groups in the sample were too small to allow a similar analysis. Finally, it is important to recall that it was not possible to follow up the children who had been adopted by the time of the study. Had they been included, the proportion who placed in $\mathrm{OHC}$ at an early age would almost certainly have been higher and mean duration of placement in $\mathrm{OHC}$ would probably be somewhat lower.

This study was funded by the Economic and Social Research Council (grant ES/L002566/1). The authors have no competing interests. 


\section{References}

1. ACTION FOR CHILDREN, NATIONAL CHILDREN'S BUREAU \& THE CHILDREN'S SOCIETY 2016. Losing in the long run. Trends in early intervention funding.

2. AL-ANSARI, B., THOW, A., DAY, C. \& CONIGRAVE, K. 2016. Extent of alcohol prohibition in civil policy in Muslim majority countries: the impact of globalization. Addiction, 111, 1703-1713.

3. ALL PARTY PARLIAMENTARY GROUP FOR CHILDREN 2017. No Good Options. Report of the Inquiry into Children's Social Care in England London National Children's Bureau.

4. ALLEN, G. 2011. Early Intervention: Smart Investment, Massive Savings, HM Government.

5. BIEHAL, N., SINCLAIR, I. \& WADE, J. 2015. Reunifying abused or neglected children: Decisionmaking and outcomes. Child Abuse \& Neglect, 49, 107-118.

6. BILSON, A. \& MARTIN, K. 2017. Referrals and Child Protection in England: One in Five Children Referred to Children's Services and One in Nineteen Investigated before the Age of Five,. The British Journal of Social Work, 47, 793-811.

7. ВООTH, T., ВООTH, W. \& MCCONNELL, D. 2005. The Prevalence and Outcomes of Care Proceedings Involving Parents with Learning Difficulties in the Family Courts. Journal of Applied Research in Intellectual Disabilities, 18, 7-17.

8. BRADSHAW, J., CHZHEN, Y. \& MAIN, G. 2017. Impact of the Recession on Children in the United Kingdom In: CANTILLON, B., CHZHEN, Y., HANDA, S. A. \& NOLAN, B. (eds.) Children of Austerity: Impact of the Great Recession on Child Poverty in Rich Countries. Oxford: Oxford University Press.

9. BRANDON, M., BAILEY, S., BELDERSON, P. \& LARSSON, B. 2014. The Role of Neglect in Child Fatality and Serious Injury. Child Abuse Review, 23, 235-245.

10. BRANDON, M., BAILEY, S., BELDERSON, P., WARREN, C., GARDNER, R. \& DODSWORTH, J. 2009. Understanding Serious Case Reviews and their impact. A Biennial Analysis of Serious Case Reviews 2005-07, London, Department for Children, Schools and Families.

11. BRANDON, M. \& THOBURN, J. 2008. Safeguarding children in the UK: a longitudinal study of services to children suffering or likely to suffer significant harm. Child \& Family Social Work, 13, 365-377.

12. BRANDON, M., THOBURN, J., LEWIS, A. \& WAY, A. 1999. Safeguarding children with the Children Act 1989, London The Stationery Office.

13. BRANDON, M., THOBURN, J., ROSE, S. \& BELDERSON, P. 2005. Living with significant harm: a follow up study, London, NSPCC.

14. BROADHURST, K., ALROUH, B., YEEND, E., HARWIN, J., SHAW, M., PILLING, M., MASON, C. \& KERSHAW, S. 2015. Connecting Events in Time to Identify a Hidden Population: Birth Mothers and Their Children in Recurrent Care Proceedings in England. The British Journal of Social Work, 45, 2241-2260.

15. BROOKES, C. \& BROCKLEHURST, P. 2014. Safeguarding Pressures Phase 4 Association of Directors of Children's Services.

16. BROOKES, C., BROCKLEHURST, P. \& ELLIS, A. 2016. Safeguarding Pressures Phase 5., Association of Directors of Children's Services

17. BROOKS, C. \& BROCKLEHURST, P. 2010. Safeguarding pressures project Phase 2: Exploring reasons and effects Association of Directors of Children's Services.

18. BROOKS, C. \& BROCKLEHURST, P. 2014. Safeguarding Pressures Phase 4, Association of Directors of Children's Services.

19. BROWN, R. \& WARD, H. 2012. Decision-making within a child's timeframe. An overview of current research evidence for family justicenprofessionals concerning child development and the impact of maltreatment, London, Department for Education

20. BYWATERS, P., BRADY, G., BUNTING, L., DANIEL, B., FEATHERSTONE, B., JONES, C., MORRIS, K., SCOURFIELD, J., SPARKS, T. \& WEBB, C. 2017. Inequalities in English child protection practice under austerity: A universal challenge? Child \& Family Social Work, n/a-n/a. 
21. BYWATERS, P., BRADY, G., SPARKS, T., BOS, E., BUNTING, L., DANIEL, B., FEATHERSTONE, B., MORRIS, K. \& SCOURFIELD, J. 2015. Exploring inequities in child welfare and child protection services: Explaining the 'inverse intervention law'. Children and Youth Services Review, 57, 98105.

22. CECIL, C., VIDING, E. I., FEARON, P., GLASER, D. \& MCCRORY, E. 2017. Disentangling the mental health impact of childhood abuse and neglect. Child Abuse \& Neglect, 63, 106-119.

23. COCHRANE, R. \& BAL, S. 1990. The drinking habits of Sikh, Hindu, Muslim and white men in the West Midlands: a community survey. Addiction, 85, 759-769.

24. DENSCOMBE, M. \& DRUCQUER, N. 2000. Diversity within ethnic groups: alcohol and tobacco consumption by young people in the East Midlands Health Education Journal, 59, 340-350.

25. DEPARTMENT FOR EDUCATION 2010. Children looked after by local authorities including adoption: 2009-10. London.

26. DEPARTMENT FOR EDUCATION 2016a. Children looked after in England (including adoption) year ending 31 March 2016 SFR 41/2016. London: Department for Education.

27. DEPARTMENT FOR EDUCATION 2016b. Expenditure by local authorities and schools on education, children and young people's services in England, 2015-16. SR63/2016, London, Department for Education,.

28. DEPARTMENT FOR EDUCATION 2017a. Characteristics of children in need: 2016 to 2017. SFR61/2017.

29. DEPARTMENT FOR EDUCATION 2017b. Children's Services: spending 2010-11 to 2015-16, London, Department for Education.

30. DEPARTMENT FOR EDUCATION 2017c. Children looked after in England (including adoption) year ending 31 March 2017 SFR 50/2017, Department for Education.

31. DEPARTMENT FOR EDUCATION AND SKILLS 2003. The Children Act Report 2002, Nottingham, DfES Publications.

32. DEPARTMENT FOR EDUCATION AND SKILLS 2004. Referrals, assessments and children and young people on child protection registers, England ñ year ending 31 March 2004

33. DEPARTMENT OF HEALTH 1995. Child Protection. Messages from the research, London, HMSO.

34. DICKENS, J. 2007. Child neglect and the law: catapults, thresholds and Delay. Child Abuse Review, $16,77-92$.

35. DICKENS, J., HOWELL, D., THOBURN, J. \& SCHOFIELD, G. 2007. Children starting to be looked after by local authorities in England: an analysis of inter-authority variation and case centred decision making. British Journal of Social Work, 37, 597-617.

36. ENGLISH, D. J. \& THE LONGSCAN INVESTIGATORS 1997. Modified Maltreatment Classification System (MMCS).

37. ENGLISH, D. J., THOMPSON, R. \& WHITE, C. 2015. Predicting risk of entry into foster care from early childhood experiences: a survival analysis using LONGSCAN data. Child Abuse and Neglect, 45, 57-67.

38. ENGLISH, D. J., UPADHYAYA, M. P., LITROWNIK, A. J., MARSHALL, J. M., RUNYAN, D. K., GRAHAM, J. C. \& DUBOWITZ, H. 2005. Maltreatment's wake: The relationship of maltreatment dimensions to child outcomes. Child Abuse \& Neglect, 29, 597-619.

39. ENGLISH, D. J. A. T. L. I. 1997. Modified Maltreatment Classification System (MMCS) [Online]. Available:

https://www.unc.edu/depts/sph/longscan/pages/maltx/mmcs/LONGSCAN\%20MMCS\%20Codin g.pdf [Accessed 29 August 2017].

40. FARMER, E. \& OWEN, M. 1995. Child Protection Practice: Private risks and public remedies, London, HMSO.

41. FARMER, E., STURGESS, W., O'NEILL, T. B. \& WIJEDASA, D. 2011. Achieiving Successful returns from care. What makes reunification work?, London, BAAF.

42. FINKELHOR, D., ORMROD, R. K. \& TURNER, H. A. 2007. Poly-victimization: A neglected component in child victimization. Child Abuse \& Neglect, 31, 7-26. 
43. FITZPATRICK, S., PAWSON, H., BRAMLEY, G. \& WILCOX., S. 2017. The homelessness monitor: England 2017, London, Crisis.

44. FLETCHER, D. R. \& WRIGHT, S. 2017. A hand up or a slap down? Criminalising benefit claimants in Britain via strategies of surveillance, sanctions and deterrence. Critical Social Policy, 0.

45. FROST, N., ABBOTT, S. \& RACE, T. 2015. Family Support: Prevention, Early Intervention and Early Help Chichester, John Wiley \& Sons.

46. GIBBONS, J., CONROY, S. \& BELL, C. 1995a. Operating the child protection system, London, HMSO.

47. GIBBONS, J., GALLAGHER, B., BELL, C. \& GORDON, D. 1995b. Development after physical abuse in early childhood, London, HMSO.

48. HASTINGS, A., BAILEY, N., BRAMLEY, G., GANNON, M., WATKINS, D. Y. J. \& FOUNDATION., R. 2015. The Cost of the Cuts: The Impact on Local Government and Poorer Communities, York Joseph Rowntree Foundation.

49. HM GOVERNMENT 2015. Working together to safeguard children. A guide to inter-agency working to safeguard and promote the welfare of children, London, Department for Education.

50. HOOD, R., GOLDACRE, A., GRANT, R. \& JONES, R. 2016. Exploring Demand and Provision in English Child Protection Services. The British Journal of Social Work, 46, 923-941.

51. HOUSE OF LORDS 2009. Judgments - R (on the application of G) (FC) (Appellant) v London Borough of Southwark (Respondents).

52. JOZWIAK, G. 2017. Trebling of households affected by benefit cap raises child poverty fears. Children and Young People Now.

53. KIM, K., MENNEN, F. E. \& TRICKETT, P. K. 2016. Patterns and correlates of co-occurrence among multiple types of child maltreatment. Child \& Family Social Work, n/a-n/a.

54. LAU, A. S., LEEB, R. T., ENGLISH, D., GRAHAM, J. C., BRIGGS, E. C., BRODY, K. E. \& MARSHALL, J. M. 2005. What's in a name? A comparison of methods for classifying predominant type of maltreatment. Child Abuse \& Neglect, 29, 533-551.

55. LITROWNIK, A. J., LAU, A., ENGLISH, D. J., BRIGGS, E., NEWTON, R. R., ROMNEY, S. \& DUBOWITZ, H. 2005. Measuring the severity of child maltreatment. Child Abuse \& Neglect, 29, 553-573.

56. LOCAL GOVERNMENT ASSOCIATION. 2017. Children's social care at breaking point, council leaders warn.

57. LORD LAMING 2003. The Victoria Climbie Inquiry: report of an inquiry by Lord Laming (Cm 5730) London, Department for Education and Skills/The Stationery Office.

58. LORD LAMING 2009. The Protection of Children in England: A Progress Report, London, The Stationery Office.

59. LUTMAN, E. \& FARMER, E. 2013. What contributes to outcomes for neglected children who are reunified with their parents? Findings from a five-year follow-up study. British Journal of Social Work, 43, 559-578.

60. MACLEOD, S., HART, R., JEFFES, J. \& WILKIN, A. 2010. The impact of the Baby Peter case on applications for care orders, NFER.

61. MASSON, J. 2008. The state as parent : the reluctant parent? The problems of parents of last resort. Journal of Law and Society, 35, 52-74.

62. MASSON, J. \& DICKENS, J. 2015. Protecting Unborn and Newborn Babies. Child Abuse Review, 24, 107-119.

63. MASSON, J., DICKENS, J., BADER, K. \& YOUNG, J. 2013. Partnership by Law. The pre-proceedings process for families on the edge of care proceedings, School of Law, University of Bristol and the Centre for Research on Children and Families, University of East Anglia.

64. MASSON, J. M., PEARCE, J. F. \& BADER, K. F. 2008. Care Profiling Study. (Ministry of Justice Research Report ; Vol. 08, No. 4). London, Ministry of Justice and Department of Children, Schools and Families.

65. MCCARDLE, L. 2014. Councils slash youth and children's centre spend by $f 200 \mathrm{~m}$. Children and Young People Now, 12 December 2014. 
66. MUNRO, E. 2011. The Munro Review of Child Protection: Final Report. A child-centred system, London, Department for Education.

67. NATIONAL AUDIT OFFICE 2016. Children in Need of Help or Protection, London, Department for Education.

68. OLIVER, C., OWEN, C., STATHAM, J. \& MOSS, P. 2001. Figures and facts: Local authority variance on indicators concerning child protection and children looked after, London, Thomas Coram Research Unit, Institute of Education, University of London.

69. OWEN, C. \& STATHAM, J. 2009. Disproportionality in Child Welfare. The Prevalence of Black and Minority Ethnic Children within the 'Looked After' and 'Children in Need' Populations and on Child Protection Registers in England, London Department for Children, Schools and Families.

70. PARTON, N. 1985. The Politics of Child Abuse, Basingstoke, Macmillan.

71. PEARS, K. C., KIM, H. K. \& FISHER, P. A. 2008. Psychosocial and cognitive functioning of children with specific profiles of maltreatment. Child Abuse \& Neglect, 32, 958-971.

72. PEARS, K. C., KIM, H. K., FISHER, P. A. \& YOERGER, K. 2013. Early School Engagement and Late Elementary Outcomes for Maltreated Children in Foster Care. Developmental Psychology, 49, 2201-2211.

73. PLATT, D. \& TURNEY, D. 2013. Making Threshold Decisions in Child Protection: A Conceptual Analysis. The British Journal of Social Work, 44, 1472-1490.

74. RADFORD, L., CORRAL, S., BRADLEY, C. \& FISHER, H. L. 2013. The prevalence and impact of child maltreatment and other types of victimization in the UK: Findings from a population survey of caregivers, children and young people and young adults. Child Abuse \& Neglect, 37, 801-813.

75. ROWLANDS, J. \& STATHAM, J. 2009. Numbers of children looked after in England: a historical analysis. Child \& Family Social Work, 14, 79-89.

76. SIDEBOTHAM, P. \& HERON, J. 2006. Child maltreatment in the "children of the nineties": A cohort study of risk factors. Child Abuse \& Neglect, 30, 497-522.

77. SIMKISS, D. E., STALLARD, N. \& THOROGOOD, M. 2013. A systematic literature review of the risk factors associated with children entering public care. Child: Care, Health and Development, 39, 628-642.

78. SINCLAIR, I., BAKER, L., LEE, J. \& GIBBS, I. 2007. The pursuit of permanence : a study of the English child care system, London, Jessica Kingsley.

79. STEVENSON, L. 2015. Social workers 'pressured' to downgrade child protection cases as referrals surge Community Care

80. STEVENSON, L. 2016. Child in need or child protection? The never-ending issue of thresholds Community Care.

81. STEVENSON, L. 2017. Four in ten children's services unable to meet legal duties due to funding pressures, finds survey. Community Care.

82. TAYLOR, J., STALKER, K. \& STEWART, A. 2016. Disabled Children and the Child Protection System: A Cause for Concern. Child Abuse Review, 25, 60-73.

83. THE TRUSSELL TRUST. 2017. End of year stats (2016-17) UK foodbank use continues to rise as new report highlights growing impact of Universal Credit rollout on foodbanks.

84. THOBURN, J., LEWIS, A. \& SHEMMINGS, D. 1995. Paternalism or partnership? Family involvement inthe child protection process, London, HMSO.

85. WADE, J., BIEHAL, N., FARRELLY, N. \& SINCLAIR, I. 2011. Caring for Abused and Neglected Children: Making the Right Decisions for Reunification or Long-Term Care, London, Jessica Kingsley Publishers.

86. WARD, H., BROWN, R. \& WESTLAKE, D. 2012 Safeguarding Babies and Very Young Children from Abuse and Neglect, Jessica Kingsley Publishers.

87. WARD, H., MUNRO, E. \& DEARDEN, C. 2006. Babies and Young Children in Care: Life Pathways, Decision-Making and Practice.

88. WHITE, O., HINDLEY, N. \& JONES, D. 2014. Risk factors for child maltreatment recurrence: An updated systematic review. Medicine, Science and the Law, 55, 259-277. 
